\title{
O LÚDICO E A INTERPRETAÇÃO NA TEORIA WINNICOTTIANA: ANÁLISE DAS RELAÇÕES RECÍPROCAS CONTIDAS NO LIVRO O BRINCAR E A REALIDADE
}

\author{
Joyce Garbosa de Azevedo; Prof. Dr. Fabio Camargo Bandeira Villela \\ Curso de Pedagogia da FCT/UNESP de Presidente Prudente; Departamento de Educação da FCT/UNESP de Presidente \\ Prudente. E-mail: joyce98ga@hotmail.com \\ Bolsa do Núcleo de Ensino - PROGRAD/ICSB.
}

\section{RESUMO}

Winnicott sofreu forte influência da prática psicanalítica de Freud e Klein, nas quais a interpretação se apresentava de forma constante e intensa. Entretanto, ao longo de sua teoria, é possível observar certo comedimento na atividade de interpretação no contexto clínico, concomitantemente com uma valorização do lúdico. Essa mudança, que se manifesta de forma incisiva nos escritos contidos no livro $O$ Brincar e a Realidade, não ocorreu de forma abrupta: ela resultou de um longo processo de pesquisa e prática clínica. Dessa forma, o objetivo do presente trabalho consiste em compreender os fatores que o conduziram à valorização do lúdico em detrimento da prática interpretativa, bem como os limites que cada uma dessas práticas apresenta no contexto clínico e, sobretudo, pelas contribuições importantes no campo da psicoterapia infantil.

Palavras-chave: Winnicott. Interpretação. Lúdico. Educação. Psicanálise.

\section{THE PLAYFULNESS AND INTERPRETATION IN THE WINNICOTTIAN THEORY: ANALYSIS OF THE RECIPROCAL RELATIONS CONTAINED IN THE BOOK PLAYING \& REALITY.}

\begin{abstract}
Winnicott suffered a strong influence of the psychoanalytic practice of Freud and Klein, in which the interpretation presented itself in a constant and intense manner. However, throughout his theory, it is possible to observe certain restraints in the activity of interpretation in the clinical context, concomitantly to an appreciation of the playfulness. This change, which manifests itself in an incisive way in the writings contained in the book Playing \& Reality, did not occur abruptly: it resulted from a long process of research and clinical practice. In this way, the objective of this paper is to understand the factors that led to the appreciation of the playfulness to the detriment of interpretative practice, as well as the limits that each of these practices presents in the clinical context and, above all, important contributions in the field of child psychotherapy.
\end{abstract}

Keywords: Winnicott. Interpretation. Playfulness. Education. Psychoanalysis. 


\section{INTRODUÇÃO}

Winnicott utilizava a interpretação, em sentido estrito, como uma ferramenta para que o paciente pudesse tomar consciência da origem de seus conflitos psíquicos, que o conduziram à análise psicanalítica. Entretanto, gradativamente, dedicou-se a investigar a área e o desenvolvimento do lúdico, que acabou por assumir parte fundamental de sua teoria acerca dos fenômenos transicionais e do espaço potencial.

Em seus escritos mais tardios do livro $O$ brincar $e$ a realidade, é explícita a crítica à interpretação como elemento central da sua clínica. A presente pesquisa busca analisar o teor de suas críticas e investigar em que medida suas formulações a respeito da interpretação acompanham os seus relatos sobre sua atividade clínica, bem como compreender o papel do lúdico em sua teoria, e também o espaço que, eventualmente, o lúdico vai ocupando em suas formulações, em detrimento da interpretação.

Apresentaremos, nos resultados do presente artigo, os temas propostos na presente pesquisa em duas seções: 1 . Interpretação e 2. Lúdico. Os dois temas têm a criatividade como elemento central comum, razão pela qual ela estará presente nas duas seções e servirá como elemento inicial que articula, em certo sentido, intrinsecamente, os dois temas. Essa separação em duas seções decorre do foco da investigação, e não da condição de poderem esses tópicos ser pensados sem referência de um ao outro. Conforme veremos, a ideia de interpretação útil para Winnicott não poderá ser analisada, desconsiderando-se o fenômeno do brincar, constitutivo do sujeito para ele.

\section{METODOLOGIA}

O presente artigo apresenta os resultados de uma pesquisa de Iniciação Científica, cuja metodologia utilizada foi a de pesquisa bibliográfica. A fim de compreender os dois tópicos que nos propomos a investigar - interpretação e lúdico - selecionamos o livro $O$ Brincar e a Realidade como fonte principal, já que ele abrange parte significativa e mais madura da obra do psicanalista Donald W. Winnicott. Todavia, o livro não apresenta uma sequência cronológica de suas ideias; foi, portanto, necessário reconstruir uma linha para compreendermos de forma clara sua posição, bem como a evolução de seu pensamento sobre o lúdico e sobre a interpretação. Além disso, outros livros foram utilizados, a fim de subsidiar a pesquisa ou para a elucidação de algum conceito.

\section{RESULTADOS}

\section{Interpretação}

Winnicott apresenta o manejo ambiental como um aspecto sumamente importante no decorrer da análise, pois, através dele, o sujeito tem a possibilidade de entrar em contato com sua realidade interna, possibilitando "que os sintomas e os problemas sejam reconhecidos por meio da criatividade" (WINNICOTT, 1975, [1971], p. 103). Ao considerarmos tal característica como tema importante em toda a sua obra, todo o processo e todos os esforços do analista em prol do paciente devem ter como objetivo que o sujeito seja capaz de viver e desfrutar uma vida criativa (WINNICOTT, 1975, [1968], p. 59).

Para Winnicott, o ambiente e o seu manejo constituem fatores importantes desde o início da vida do indivíduo, a fim de que tudo se desenvolva tranquilamente, o que, evidentemente, não significa que, com um ambiente favorável, haverá a ausência de problemas, desafios e dificuldades.

A partir do estado de não-integração se produz a integração por breves momentos ou períodos, e só gradualmente o estado geral de integração se transforma em fato. Fatores internos podem contribuir para promover a integração; como exemplo temos a exigência instintiva ou a expressão agressiva, cada uma delas sendo precedida por uma convergência aglutinadora do self como um todo. Nestes momentos, a consciência se 
torna possível, pois ali existe um self para tomar consciência. A integração também é estimulada pelo cuidado ambiental. Em psicologia, é preciso dizer que o bebê se desmancha em pedaços a não ser que alguém o mantenha inteiro. Nestes estágios o cuidado físico é um cuidado psicológico. (WINNICOTT, 1990, p. 137).

Semelhante ao manejo ambiental necessário para que ocorra o processo de integração do self da criança, na prática clínica de psicoterapia, o autor também aponta o manejo ambiental como uma característica que delineia e enriquece a experiência do paciente. "[...] A pessoa a quem estamos tentando ajudar necessita de uma nova experiência, num ambiente especializado. A experiência é a de um estado não-intencional. (WINNICOTT, 1975, [1971], p. 81).

Assim, quando o analista é capaz de oferecer o holding, isso é, a capacidade de apoiar, segurar e manejar emocionalmente todo o processo, o paciente tende a regredir e a elaborar uma necessidade ou uma dificuldade que o impede de viver criativamente. Portanto, a regressão constitui um aspecto e um momento de suma importância para a continuidade do desenvolvimento no processo que o paciente necessita experimentar, tendo em vista o alcance de uma experiência satisfatória que consiste no encontro e no amadurecimento do próprio self (WINNICOTT, 1975 [1971], p. 80).

Entretanto, apesar de enfatizar o holding como um aspecto necessário para que o sujeito possa elaborar os conteúdos psíquicos, é necessário que o analista esteja atento a outro fator igualmente importante: o timing. Winnicott aponta que a psicoterapia deve ocorrer conforme o "processo natural", isso é, no tempo do paciente, pois, como resultado das experiências propiciadas, o próprio sujeito alcançará a compreensão de tais problemas ou dificuldades que interferem objetiva ou subjetivamente em sua vida.

Todavia, Winnicott efetua algumas interpretações, em sentido estrito, profundas e reveladoras, como uma forma de elucidar ao paciente alguns aspectos que emergem no decorrer da análise.

Além disso, Winnicott parece apontar algumas condições para que uma interpretação seja bem efetuada e produza os efeitos necessários para que a análise continue se desenrolando de forma adequada: o processo e as ações que decorrem no curso da análise devem ser em função e no tempo do sujeito e, sobretudo, devem ter como cerne o alcance do criatividade, pois, é por meio desse processo de descoberta que o sujeito reconhece o sentido do seu próprio self, permitindo que aspectos incompreendidos se manifestem e sejam compreendidos pelo paciente. Assim, é necessário para a interpretação, a relação de confiança, a criação de um holding de sustentação emocional e o adequado timing frente ao que está emergindo no processo analítico.

Todas as ações do analista devem ser realizadas de modo que o sujeito alcance a capacidade de brincar, ou seja, mesmo a interpretação deve ser efetuada intencionalmente para conduzi-lo a esse fim, caso contrário, a interpretação ou qualquer outro esforço do analista será insignificante para o paciente, já que o sentido e o significado se encontram na descoberta da criatividade que se relaciona ao "estar vivo" (WINNICOTT, 1975 [1971], p. 98).

Interpretação fora do amadurecimento do material é doutrinação e produz submissão [...]. Em consequência, a resistência surge da interpretação dada fora da área da superposição do brincar em comum de paciente e analista. Interpretar quanto o paciente não tem capacidade para brincar, simplesmente não é útil, ou causa confusão. Quando existe um brincar mútuo, então a intepretação, segundo os princípios psicanalíticos aceitos, pode levar adiante o trabalho terapêutico. Esse brincar tem de ser espontâneo, e não submisso ou aquiescente, se é que se quer fazer psicoterapia. (WINNICOTT , 1975 [1971], p. 75)

Partindo desse ponto, podemos perceber que, mesmo com todas as críticas que Winnicott realiza no decorrer da apresentação de seu trabalho, a interpretação não é totalmente deixada de lado, desde que ela seja realizada no momento em que o brincar se tornou mútuo e houve o 
estabelecimento de uma relação entre ambos. Ao contrário, como já afirmado pelo autor, se a interpretação for efetuada "fora do amadurecimento do material" psíquico, então haverá fortes represálias do inconsciente, no sentido de elaborar resistências e defesas organizadas que dificultam a continuidade do processo terapêutico.

Logo, a interpretação deve ocorrer no espaço da superposição da área do brincar comum entre a criança e o analista, isso é, quando o sujeito, apoiado pelo ambiente, conseguir entrar em contato com a sua realidade psíquica e interna, mas, concomitantemente, manter contato com a realidade objetivamente percebida. A área de superposição, portanto, possibilita que a realidade interna e a externa se inter-relacionem, e é nesse espaço que a interpretação deve ocorrer, pois há a interação dos conteúdos advindos do mundo interno e da realidade externa, enriquecendo as experiências do sujeito. Em suma, a interpretação deve ocorrer quando o paciente se tornar ciente de sua necessidade, dificuldade ou falha no processo de seu desenvolvimento psíquico, sendo emocionalmente sustentado pelo holding.

A interpretação, em sentido estrito, é sugerida especialmente no ambiente clínico, sobretudo nos casos em que o sujeito não foi capaz de alcançar o estado de integração, então, exige do analista uma adaptação emocional, física e ambiental às necessidades do paciente que emergirem na análise, até que o processo de integração do EU seja finalizado. Além disso, o fato de o analista estar presente e permanecer vivo durante o processo de integração, efetuado através de uma profunda regressão, contribui para a continuidade das experiências de manejo que esse analista deverá proporcionar ao sujeito, até que ele se organize como uma pessoa total, dotada de características e experiências próprias.

[...] A lentidão do processo analítico é a manifestação de uma defesa que o analista tem de respeitar, tal como respeitamos todas as defesas. [...], quando, finalmente, o paciente se torna apto a trazer assuntos profundamente sepultados para o conteúdo da transferência, concedendo, por esse meio, oportunidade para a interpretação mutativa. 0 analista, pela interpretação, demonstra o grau de comunicação que é capaz de receber do paciente. (WINNICOTT, 1975 [1971], p. 103)

Winnicott, portanto, demonstra e assume que a interpretação deve fazer parte do processo analítico, desde que seja utilizada no timing oportuno, isto é, quando o sujeito for capaz de compreender e trazer para o ambiente de análise assuntos, problemas ou dificuldades que antes eram totalmente desconhecidos por ele. É por esse motivo que o autor sugere a necessidade de esperar o momento oportuno para a interpretação e, mesmo se algum aspecto estiver totalmente claro para o analista, mas o paciente não tiver chegado à compreensão mínima do problema, será preciso que ele retenha a sua interpretação e sua compreensão acerca do paciente para si próprio (WINNICOTT , 1975 [1971], p. 83).

Será preciso, sobretudo, que seja capaz de esperar e sustentar o holding até que o paciente tenha consciência e acesso àquilo que antes era incompreensível ou mesmo inadmissível para ele próprio, possibilitando-lhe uma gradual elaboração e compreensão, que consistirá no sentido e no significado do processo.

Essa atitude permite ao paciente a continuidade natural do fluxo associativo das ideias, seja na análise de crianças ou na psicoterapia com os adultos, possibilitando que o sujeito se surpreenda com sua própria compreensão e conhecimento acerca da situação que antes estava indisponível ao seu consciente, evitando o surgimento de defesas psíquicas que poderiam ser desencadeadas, no caso de alguma interpretação fora do timing e da compreensão que o paciente era capaz naquele momento.

Ao efetuar a interpretação no timing oportuno, o analista não somente elucida um conteúdo inconsciente, mas demonstra ao paciente o que compreende e, ao mesmo tempo, propicia um holding ambiental que sustenta o processo de transferência, permitindo, portanto, ao 
sujeito uma continuidade no fluxo de associações e, posteriormente, que ele próprio elabore tais conteúdos no decorrer do processo.

Em suma, a interpretação no timing oportuno, deve visar somente à continuidade e ao desenvolvimento do processo em que o paciente está submerso, a fim de que o sujeito seja capaz de desfrutar uma vida criativa.

\section{Lúdico}

Pensando na psicoterapia com crianças, a brincadeira assumiu sua nova forma de análise, pois, a por meio dela, é possível e mais provável a aproximação entre aquilo que é subjetivamente percebido e aquilo que é objetivamente percebido, constituindo o cerne de todo o processo que envolve o desenvolvimento emocional do sujeito, a integração do self e a formação da personalidade de forma criativa e peculiar.

No decorrer do desenvolvimento da criança, diversas forças ambivalentes impulsionam e orientam a formação do seu self e, gradativamente, sua forma de relacionamento com o mundo interno e externo. O brincar, como forma de expressão dos sentimentos e desejos, tende a auxiliar a criança no processo de elaboração dos conflitos internos. Por esse motivo, o brincar assume uma posição importante na teoria de Winnicott e constitui "[...] por si mesmo [...] uma psicoterapia que possui aplicação imediata e universal, e inclui o estabelecimento de uma atitude social positiva com respeito ao brincar." (WINNICOTT, 1975, p. 74). Além disso, o brincar está estritamente relacionado à criatividade que, segundo Winnicott (WINNICOTT, 1975 [1971], p. 98), é uma característica inata de todo ser vivo.

O espaço potencial ou intermediário abriga e enriquece as experiências criativas do sujeito. Entretanto, antes do brincar em sentido estrito, a criança tende a formular mecanismos de se relacionar com a realidade interna e externa de forma conjunta.

Um desses mecanismos é o da constituição do objeto transicional, que assume uma característica vital, pois possibilita à criança ricas experiências e, sobretudo, a evolução de sua experiência criativa. Por isso, é importante que a criança tenha a liberdade de manejá-lo de acordo com sua necessidade e que ele seja mantido e preservado da forma que a criança o deixar, seja sujo ou com um cheiro desagradável (WINNICOTT, 1975 [1951], p. 17).

Além disso, os fenômenos transicionais - que se manifestam com o enrolar o cabelo com o dedo, ou a sucção do próprio polegar ou na carícia do próprio corpo - desempenham a mesma função que os objetos transicionais: a de constituição dessa zona intermediária e ponte entre realidade interna e realidade externa, tão fundamental no desenvolvimento psíquico da criança.

Gradativamente, as manifestações desses fenômenos e a adoção de objetos vão sendo abandonados pela criança - embora ainda possam sobrevir em alguns momentos, já que o desenvolvimento não se caracteriza como um processo linear. Todavia, as experiências que ela obteve, continuam vivas nessa terceira área psíquica, que constitui o espaço potencial, uma área de experimentação, e que, posteriormente, assume a forma lúdica: o brincar em sentido amplo, compartilhável com outras crianças.

$\mathrm{Na}$ brincadeira, a criança tem liberdade para criar e recriar o mundo conforme sua visão, por meio de uma linguagem própria que the permite compreender aspectos subjetivos do seu mundo interno, as exigências do mundo externo e, sobretudo, tem a possibilidade de manifestar suas fantasias, seus desejos e sentimentos por meio da criatividade.

[...] propiciar oportunidade para a experiência amorfa e para os impulsos criativos, motores e sensórios, que constituem a matéria-prima do brincar. É com base no brincar, que se constrói a totalidade da existência experiencial do homem. Não somos mais introvertidos ou extrovertidos. Experimentamos a vida na área dos fenômenos transicionais, no excitante entrelaçamento da subjetividade e da observação objetiva, e numa área intermediária entre a realidade interna do indivíduo e a realidade compartilhada do mundo externo aos indivíduos. (WINNICOTT, 1975 [1971], p. 93). 
Além de o brincar possibilitar a experimentação da fantasia, auxiliar na elaboração de conflitos e na descoberta envolvente do meio, quando esse brincar torna--se compartilhado, a brincadeira tende também a expandir o self do indivíduo, isso é, tende a enriquecer significativamente sua personalidade. Visto sob outra perspectiva, as experiências adquiridas tendem a dar um novo sentido a esse campo que se manifesta durante toda a vida do sujeito, mas que é enriquecido principalmente no período da infância nas primeiras experiências criativas e, posteriormente, na própria brincadeira.

[...] a brincadeira que é universal e que é própria da saúde: o brincar facilita o crescimento e, portanto, a saúde; o brincar conduz aos relacionamentos grupais; o brincar pode ser uma forma de comunicação na psicoterapia; finalmente, a psicanálise foi desenvolvida como forma altamente especializada do brincar, a serviço da comunicação consigo mesmo e com os outros. (WINNICOTT, 1975 [1968], p. 63)

$\mathrm{Na}$ vida adulta, o espaço potencial continua manifestando-se, entretanto, sob outras formas, como por meio da experiência e expressão cultural que, segundo Winnicott (1975 [1967]), "é comum da humanidade", mas que, ao mesmo tempo, exige algo de individual e próprio de cada sujeito: a sua experiência e contribuição nesse vasto campo e que, além disso, decorre do brincar.

\section{DISCUSSÃO}

Winnicott inicia seu trabalho sob forte influência da ideia da importância central da interpretação na clínica psicanalítica. Gradativamente, passa a considerar a interpretação como um obstáculo ao desenvolvimento da análise. Entretanto, podemos perceber pela leitura de sua obra que, mesmo criticando claramente a interpretação, o autor ainda faz uso dela em sentido estrito: revelando conteúdos completamente inconscientes ao sujeito ou, em sentido ampliado: quando o paciente já tem consciência do conteúdo psíquico antes oculto.

Ao distanciar-se da interpretação como prática clínica central, o autor aproxima-se do lúdico e da criatividade, em grande parte como decorrência de sua pesquisa no campo dos fenômenos transicionais. Winnicott postula que a criatividade e o seu uso na realidade externa e objetiva auxilia o indivíduo a superar e manejar as diferentes emoções, ou seja, a criatividade é parte de um sujeito emocionalmente maduro e saudável.

\section{CONCLUSÃO}

A brincadeira está interligada à criatividade e, portanto, ao mundo interno da criança e, ao mesmo tempo, relaciona-se com a realidade externa. Quando a criança brinca é sinal de que o desenvolvimento emocional está ocorrendo de forma saudável, pois, por meio do brincar, a criança tem a possibilidade de compreender a realidade externa e de elaborar os conflitos internos que, quando não compreendidos, podem dificultar seu desenvolvimento. A psicanálise clínica, mesmo de adultos, só teria efetividade nesse contexto criativo, em que analista e paciente desenvolvem um brincar especializado - a própria sessão psicanalítica ou, em sentido mais abrangente, o próprio atendimento clínico - somente em função do qual a interpretação faria sentido. Assim, Winnicott articula os fenômenos da interpretação e do lúdico, condicionando a eficácia daquela à instauração ou à prevalência desse ambiente lúdico especializado, típico da psicanálise, no sentido clínico do termo.

\section{REFERÊNCIAS}

WINNICOTT, D. W. A criança e o seu mundo. 6.ed. Rio de Janeiro: LTC, 2015.

WINNICOTT, D. W. A família e o desenvolvimento individual. 4. ed. São Paulo: Martins Fontes, 2011. 
WINNICOTT, D. W. Natureza Humana. s. e. Rio de Janeiro: Imago ed., 1990.

WINNICOTT, D. W. O Brincar e a Realidade. Rio de Janeiro: Imago ed., 1975.

WINNICOTT, D. W. Retraimento e Regressão. In: WINNICOTT, D. W. Holding e Interpretação. 3. ed. São Paulo: Martins Fontes, 2010. 